\title{
Familial risks for gallstones in the population of Sweden
}

\author{
Kari Hemminki, ${ }^{1,2}$ Otto Hemminki, ${ }^{3,4}$ Asta Försti, ${ }^{1,2}$ Kristina Sundquist, ${ }^{2,5,6}$ \\ Jan Sundquist, ${ }^{2,5,6}$ Xinjun $\mathrm{Li}^{2}$
}

To cite: Hemminki K, Hemminki 0, Försti A, et al. Familial risks for gallstones in the population of Sweden. BMJ Open Gastro 2017;4:e000188. doi:10.1136/ bmjgast-2017-000188

Received 13 November 2017 Revised 30 November 2017 Accepted 15 December 2017

Check for updates

${ }^{1}$ Division of Molecular Genetic Epidemiology, German Cancer Research Center (DKFZ), Heidelberg, Germany ${ }^{2}$ Center for Primary Health Care Research, Lund University, Helsinki, Finland

${ }^{3}$ Department of Abdominal Surgery and Urology, Helsinki University Hospital, Helsinki, Finland

${ }^{4}$ Cancer Gene Therapy Group, Faculty of Medicine, University of Helsinki, Helsinki, Finland ${ }^{5}$ Department of Family Medicine and Community Health, Icahn School of Medicine at Mount Sinai, New York, USA

${ }^{6}$ Department of Population Health Science and Policy, Icahn School of Medicine at Mount Sinai, New York, USA

Correspondence to Dr Kari Hemminki; k.hemminki@dkfz.de

\begin{abstract}
Objectives Gallstone disease (cholelithiasis) has a familial component, but detailed data on the modification of familial risk are lacking. Using nationwide hospital and population records, we aimed to determine detailed familial risks for medically diagnosed gallstone disease. Design Subjects were obtained from the Multigeneration Register, which contains family data on the Swedish population, and patients with gallstone disease were identified from the Hospital Discharge Register (1964-2015) and the Outpatient Register (2001-2015). Standardised incidence ratios (SIRs) were calculated as the ratio of observed to expected number of cases.

Results Gallstone disease was diagnosed in 660732 patients, with an overall incidence of 131 per 100000 person-years. Familial cases accounted for $36.0 \%$ of all patients with gallstone disease. Of these, $50.9 \%$ had a parental family history (SIR 1.62), 35.1\% had a sibling history (SIR 1.75) and $14.0 \%$ had a parental+sibling history (SIR 2.58). Among a total of 54630 affected siblings, $84.4 \%$ were sibling pairs (SIR 1.55). However, the remaining $15.6 \%$ of the affected siblings constituted the high-risk group of multiple affected siblings and an SIR >10; these persons accounted for $7.7 \%$ of all familial cases. The spousal risk was only slightly increased to 1.18 .
\end{abstract}

Conclusions Overall, the results point to the underlying genetic causes for the observed familial clustering, which may involve polygenic gene-environmental interactions for most familial cases but high-risk genes in close to $10 \%$ of cases. Family histories should be taken into account in the medical setting and used for counselling of at-risk individuals.

\section{INTRODUCTION}

Gallstones grow inside the gallbladder or biliary tract and if symptomatic they constitute gallstone disease or cholelithiasis. ${ }^{1}$ Gallstones may be classified by their composition into common cholesterol gallstones and bilirubin stones, by their colour into black pigment stones caused by haemolysis and brown pigment stones caused by obstructed or infected bile ducts, and by their localisation most commonly in the gallbladder or in the biliary tract. $^{2}$ Over $10 \%$ of the US and European populations develop gallstones and the condition is becoming more
Summary box

What is already known about this subject?

- It is known that gallstone disease runs in families, but how the risk is modified by a detailed family history is not known.

- Germline gene variants have been associated with the risk of gallstone disease.

What are the new findings?

- Familial cases accounted for $36.0 \%$ of all patients with gallstone disease.

- Of familial cases, $50.9 \%$ had a parental family history with a standardised incidence ratio (SIR) of 1.62 compared with those without the family history.

- Of familial cases, $35.1 \%$ had a sibling history with an SIR of 1.75 .

- Of familial cases, $14.0 \%$ had a parental+sibling history with an SIR of 2.58 .

- Among the affected siblings, $15.6 \%$ were from families of two or more siblings diagnosed with an $\mathrm{SIR}>10$

The spousal risk was only 1.18 .

How might it impact on clinical practice in the foreseeable future?

- Family histories should be taken when patients are diagnosed with gallstones.

- It would be important to identify the high-risk families and target counselling at patients and healthy individuals from such families.

widespread due to the increasing prevalence of risk factors such as obesity and physical inactivity. ${ }^{13}$ Other risk factors are female sex, high age, pregnancy, certain ethnic background, family history and genetics. ${ }^{3}$ However, the female excess incidence could not be found in Taiwanese vegetarians. ${ }^{4}$ Gallstone disease has important medical consequences and costs; prevention should be of high priority. ${ }^{56}$

Based on familial clustering of gallstone disease, a 2.2-fold to 4.5-fold elevated risk has been reported in case-control studies among first-degree relatives and heritability estimates of $25 \%$ to $29 \%$ have been 
derived from family and twin studies. ${ }^{7-9}$ In one study, young women were at particular risk and the authors suggested that 'female relatives of young gallstone patients should be routinely screened for gallstones'. A family study from the 1960s found no increased risk for gallstones among spouses, which suggests purely genetic origin for the familial clustering of gallstone disease. ${ }^{10}$ Several susceptibility genes have been identified, including apolipoproteins E (APOE) and B (APOB), cholesterol ester transporting protein (CETP), cholesterol 7 $\alpha$-hydroxylase (CYP7A1), cholecystokinin receptor A (CCKAR) and $L D L$ receptor $(L D L R){ }^{3}$ In some genome-wide association studies (GWASs), low-risk variants for the hepatic cholesterol secretion (ABCG8 $19 H$ and $A B C B 4$ ) have been associated with gallstone disease. It has been estimated that the mutations in the hepatic cholesterol transporter ABCG8 confer the largest share of the genetic risk of developing gallstones. ${ }^{1}$ A meta-analysis of GWASs of individuals of European ancestry identified genetic risk variants for gallstone disease in $A B C G 8$, TM4SF4, SULT2A1 and CYP7A1 genes. ${ }^{11}$

In view of the known inaccuracies in reporting family histories in case-control studies and the limited size of the published studies, we considered it timely to revisit familial risks of gallstone disease using the national cohort of Swedish families whose gallstones were medically diagnosed. ${ }^{12-15}$ In addition to the estimation of familial risks between genetically related relatives, we wanted to assess disease sharing between spouses in order to reconsider the contribution of the shared environment in adulthood. The study covered 15.8 million individuals and 660732 patients with gallstones.

\section{PATIENTS AND METHODS}

Family relationships were obtained from the Multigeneration Register, which contains family data on the Swedish population and spans more than a century. 'The offspring generation' was born after 1931 and 'the parental generation' was born any time earlier. By the year 2015, the offspring generation had reached the age of 83 years; siblings can be defined only in the offspring generation. The offspring generation comprised 8.9 million index individuals in total. Patients with gallstones were identified using the nationwide Swedish Hospital Discharge Register (1964-2015) and the Outpatient Register (2001-2015). The first gallstone diagnosis in either register was considered and a patient was only entered once. Information from the registers was linked at the individual level via the national 10-digit civic registration number, which is issued to all permanent residents in Sweden on birth or immigration to the country. In the linked dataset, civic registration numbers were replaced with serial numbers to ensure anonymity. Revisions 7 (19641986), 9 (1987-1996) and 10 (1997-) of the International Classification of Diseases were used to identify gallstone diagnostic codes.
Table 1 Population and number of cases of gallstone disease in Sweden, 1964-2015

\begin{tabular}{llll}
\hline & Men & Women & All \\
\hline $\begin{array}{l}\text { Total population } \\
\text { Diagnosis of gallstone disease }\end{array}$ & 8025741 & 7790505 & 15816246 \\
$\mathrm{n}$ & 224475 & 436257 & 660732 \\
$\begin{array}{l}\text { Mean age at } \\
\text { diagnosis }\end{array}$ & $60.0 \pm 16.6$ & $53.5 \pm 18.8$ & $55.7 \pm 18.3$ \\
$\begin{array}{l}\text { Median age at } \\
\text { diagnosis }\end{array}$ & 61 & 54 & 57 \\
$\begin{array}{l}\text { Incidence rate per } \\
100 \text { 000 person- } \\
\text { years* }\end{array}$ & 87.8 & 176.2 & 131.1 \\
\hline
\end{tabular}

*Age adjusted for European standardised population.

Standardised incidence ratios (SIRs) were calculated as the ratio of observed to expected number of cases. The expected numbers were calculated for all individuals without a history of gallstones (essentially the whole Swedish population), and the rates were standardised by 5-year-age, gender, period (5-year-group), socioeconomic status and residential area. The 95\% CI of the SIR was calculated assuming a Poisson distribution. SIRs were calculated for offspring depending on the affected probands: parent, siblings or parents and siblings.

In order to assess possible roles of environmental risk factors for familial clustering of gallstones, we determined SIRs for gallstones in wives when husbands were diagnosed with gallstones and similarly for husbands when wives were diagnosed with gallstones. The period at risk for spouses was defined to start at the birth year of their first common child or at the first year that they were registered as living at the same address, whichever came first. The follow-up was terminated at gallstone diagnosis, death or when spouses no longer lived at the same address. ${ }^{16}$

The study was approved by the Regional Ethical Review Board of Lund University (no. 2012/795).

\section{RESULTS}

Patient numbers and mean diagnostic ages for gallstone disease are shown in table 1 . The total population included 15.8 million individuals with men slightly outnumbering women. Patients with gallstone disease amounted to 660732 . Women $(436257,66.0 \%$ ) significantly outnumbered men (224 475). Mean and median diagnostic ages (ie, first hospital contact) were 55.7 and 57 years, respectively. The overall incidence was 131 per 100000 person-years.

Familial risks are shown in table 2 in age groups of the offspring generation 0 to 83 year old for whom familial risks were calculated. The overall familial risks were almost identical for men (SIR 1.79) and women (SIR 1.75), giving an overall SIR of 1.76. However, 
Table 2 Familial SIR of gallstone disease by age groups

\begin{tabular}{|c|c|c|c|c|c|c|c|c|c|}
\hline \multirow[b]{2}{*}{ Age at diagnosis (years) } & \multicolumn{3}{|l|}{ Men } & \multicolumn{3}{|c|}{ Women } & \multicolumn{3}{|l|}{ All } \\
\hline & 0 & SIR & $95 \% \mathrm{Cl}$ & 0 & SIR & $95 \% \mathrm{CI}$ & $\mathbf{0}$ & SIR & $95 \% \mathrm{Cl}$ \\
\hline $0-9$ & 46 & 1.59 & 1.16 to 2.12 & 55 & 2.22 & 1.67 to 2.90 & 101 & 1.88 & 1.53 to 2.28 \\
\hline 20-29 & 2667 & 2.48 & 2.38 to 2.57 & 15808 & 2.20 & 2.17 to 2.23 & 18475 & 2.24 & 2.20 to 2.27 \\
\hline 30-39 & 6293 & 2.11 & 2.06 to 2.16 & 19471 & 1.84 & 1.82 to 1.87 & 25764 & 1.90 & 1.88 to 1.92 \\
\hline $50-59$ & 7763 & 1.67 & 1.64 to 1.71 & 13474 & 1.55 & 1.52 to 1.58 & 21237 & 1.59 & 1.57 to 1.61 \\
\hline $60+$ & 7950 & 1.46 & 1.43 to 1.49 & 10558 & 1.40 & 1.38 to 1.43 & 18508 & 1.43 & 1.41 to 1.45 \\
\hline All & 33651 & 1.79 & 1.77 to 1.81 & 77622 & 1.75 & 1.73 to 1.76 & 111273 & 1.76 & 1.75 to 1.77 \\
\hline
\end{tabular}

O, observed number of cases; SIR, standardised incidence ratio.

female SIRs were higher than male SIRs until age 19, but at higher age there was a male excess. The maximal SIR was 2.68 for men and 3.01 for women; this was reached at age 10 to 19 years, after which age the SIR uniformly decreased to age $60+$ years. The total number of familial gallstone disease patients was 111273 in the offspring generation. The total number of patients with gallstone in the offspring generation numbered 308 949, thus familial cases accounted for $36.0 \%$ of all patients with gallstone disease.

Age-specific incidence for all gallstone disease, with and without family history, is shown in figure 1. On top, female familial and non-familial incidence increased steeply up to ages 30 to 34 , and after 34 years less steeply to age $75+$ years. In bottom, male familial and non-familial incidence showed a continuous increase reaching the female rates at age $75+$ years. At the reproductive age, from 20 to 34 years, female familial and non-familial rates exceeded the male rates up to 5 -fold.

Table 3 shows familial risks for gallstone disease by different probands. The SIRs were highest (2.58 for men and women combined) when both a parent and a sibling were diagnosed with gallstone disease, compared with 1.62 when only a parent or 1.75 when only a sibling was diagnosed. The SIR was 2.44 when both parents were affected. Risks for sons were 1.71 when fathers were affected compared with daughters' SIR of 1.62 when mothers were affected. The difference was not large, but because of large case numbers, it was significant (ie, 95\% CIs did not overlap). Table 3 also shows spousal risks, 1.18 for husbands of affected wives and also 1.18 for wives of affected husbands.

In table 4, we show familial risk for gallstone disease by the number of affected siblings. For both sexes combined, the SIR was 1.55 when one sibling was affected, and it increased to 10.16 for persons with two affected siblings. SIRs remained at that level if up to four or more siblings were affected. However, considering persons diagnosed before age 30 years, there was a continuous increase in risk in these four proband categories, 2.06, $11.77,14.18$ and 17.02 , respectively.
Male risks were uniformly higher than female risks, and the difference between SIRs increased by the number of affected siblings and was always highest in the early onset group, for example, 39.80 in men diagnosed before age 30 and who had four or more affected siblings compared with 15.06 in women in this category. Data on siblings are shown figure 2 , together with parental and spousal SIRs from table 3 .

\section{DISCUSSION}

The present study used nationwide hospital records on 660732 inpatients and outpatients who were medically diagnosed with gallstone disease. The national cohort design is, in principle, unbiased and the results constitute by far the largest family study on gallstone disease yet published. The main novel finding was the complex population architecture of familial gallstone disease, with strong dependence of the risk on the age of onset and the number of affected family members, signalling genetic effects. Also, some unexpected results were found for the gender. Spousal correlation associated with gallstone disease, which signals environmental contributions, was modest. However, it was higher than reported in the literature but perhaps not unexpected because of the number of known environmental risk factors. ${ }^{10}$ The limitations of the study were unavailability of primary care data, which may include persons with transient abdominal pain.

Familial cases, that is, persons in the offspring generation with a parent or a sibling with gallstone disease, accounted for $36.0 \%$ of all patients. The overall incidence of gallstone disease (131 per 100000 personyears) was doubled in women compared with men. The largest difference between female and male incidence rates was noted at reproductive ages. Relatively few incidence data are available from other countries. In the UK, age-standardised hospital admission rates for gallstone disease increased from 68.7 to 104.9 per 100000 population between 1989/1990 and 1999/2000; female rates were more than doubled compared with men. ${ }^{17}$ 


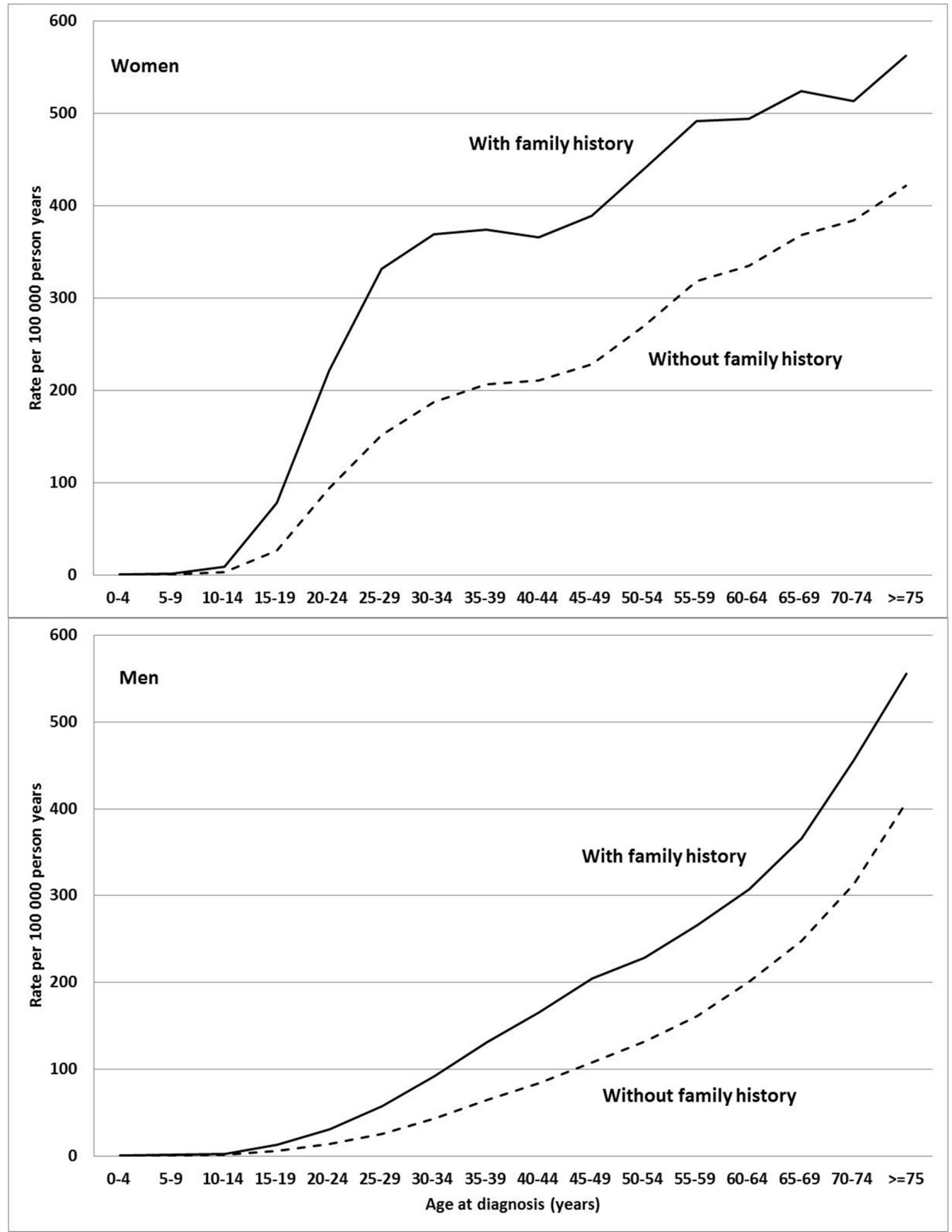

Figure 1 Incidence of gallstone disease in women (top) and men (bottom) per 100000 person-years. Note that the difference between the curves is an estimate of crude incidence rates.

The increasing trend appears to continue in developed countries. ${ }^{1} 1819$ In Taiwan, hospitalisation rates were about 60 per 100000 for both men and women around the year $2000 .^{20}$ It is noteworthy if the female excess in gallstone disease is a feature of western populations.

The total number of familial gallstone disease patients was 111273 in the offspring generation 0 to 83 years old. Of these, $50.9 \%$ had a parental family history (SIR 1.62), 35.1\% had a sibling family history (SIR 1.75 ) and $14.0 \%$ had a parental+sibling family history (SIR 2.58). Among a total of 54626 affected siblings, $84.4 \%$ were sibling pairs (SIR 1.55 ). However, the remaining $15.6 \%$ of the affected siblings constituted the high-risk group with an SIR $>10$; these 8527 persons accounted for $7.7 \%$ of all affected offspring. In this high-risk group, those diagnosed before the age of 30 years were at the highest risk, particularly if they were men. It is noteworthy that despite the doubled incidence in women, the overall familial risks were only marginally higher in men, but in the highest risk groups, they were much higher. Thus, the citation from the Introduction 'female relatives of young gallstone patients should be routinely screened for gallstones' should be modified from focusing on gender 
Table 3 Familial SIR of gallstone disease

\begin{tabular}{|c|c|c|c|c|c|c|c|c|c|}
\hline \multirow[b]{2}{*}{ Probands } & \multicolumn{3}{|l|}{ Men } & \multicolumn{3}{|c|}{ Women } & \multicolumn{3}{|l|}{ All } \\
\hline & 0 & SIR & $95 \% \mathrm{Cl}$ & 0 & SIR & $95 \% \mathrm{Cl}$ & 0 & SIR & $95 \% \mathrm{Cl}$ \\
\hline Parent & 21345 & 1.65 & 1.63 to 1.68 & 50910 & 1.63 & 1.62 to 1.64 & 72255 & 1.64 & 1.62 to 1.65 \\
\hline Both parents & 1682 & 2.63 & 2.50 to 2.76 & 3710 & 2.37 & 2.29 to 2.44 & 5392 & 2.44 & 2.38 to 2.51 \\
\hline Father & 8688 & 1.71 & 1.68 to 1.75 & 18991 & 1.55 & 1.53 to 1.57 & 27679 & 1.60 & 1.58 to 1.62 \\
\hline Mother & 14341 & 1.57 & 1.55 to 1.60 & 35629 & 1.62 & 1.60 to 1.64 & 49970 & 1.61 & 1.59 to 1.62 \\
\hline Sibling & 17182 & 1.82 & 1.79 to 1.85 & 37448 & 1.76 & 1.75 to 1.78 & 54630 & 1.78 & 1.77 to 1.80 \\
\hline $\begin{array}{l}\text { Both parent and } \\
\text { sibling }\end{array}$ & 4876 & 2.69 & 2.62 to 2.77 & 10734 & 2.53 & 2.49 to 2.58 & 15610 & 2.58 & 2.54 to 2.62 \\
\hline Only parent & 16469 & 1.64 & 1.61 to 1.66 & 40174 & 1.62 & 1.60 to 1.63 & 56643 & 1.62 & 1.61 to 1.64 \\
\hline Only sibling & 12306 & 1.78 & 1.75 to 1.81 & 26712 & 1.74 & 1.72 to 1.76 & 39018 & 1.75 & 1.73 to 1.77 \\
\hline Spouses & 20704 & 1.18 & 1.17 to 1.20 & 20704 & 1.18 & 1.17 to 1.20 & 41408 & 1.18 & 1.17 to 1.19 \\
\hline
\end{tabular}

O, observed number of cases; SIR, standardised incidence ratio.

to a defined family history. ${ }^{7}$ The high-risk group constitutes families with at least two affected siblings.

In conclusion, the present results provide qualified evidence for the familial risk in gallstone disease, which covered $36.0 \%$ of all patients with gallstone disease in our study. The patterns of familial clustering suggest that the large majority of the population, with one affected family member, are at a 1.6-fold to 1.7-fold risk of being hospitalised for gallstone disease. A smaller group, which has both parents or a parent and a sibling diagnosed with gallstone disease, run a higher risk of about 2.5. The high-risk population constitutes those with at least two siblings, some $7.7 \%$ of all familial gallstone disease patients, and their risk is over 10-fold the background rate. One can assume that the majority of the familial risk is contributed by gene-environment interactions at a polygenic background of common low-risk variants while the high-risk population carries gene variants with high to moderate penetrance. ${ }^{13} 11$ It would be useful that clinical guidelines for gallstone disease would also consider prevention and counselling about avoidance of risk factors with a focus on patients and healthy individuals from high-risk families. ${ }^{21}$ The present results about familial risk should reassure

Table 4 SIR of gallstone disease among siblings

\begin{tabular}{|c|c|c|c|c|c|c|c|c|c|}
\hline \multirow[b]{2}{*}{ Siblings } & \multicolumn{3}{|l|}{ Men } & \multicolumn{3}{|l|}{ Women } & \multicolumn{3}{|l|}{ All } \\
\hline & 0 & SIR & $95 \% \mathrm{Cl}$ & 0 & SIR & $95 \% \mathrm{Cl}$ & 0 & SIR & $95 \% \mathrm{Cl}$ \\
\hline One sibling & 14416 & 1.56 & 1.54 to 1.59 & 31683 & 1.54 & 1.52 to 1.56 & 46099 & 1.55 & 1.53 to 1.56 \\
\hline$<30$ & 1043 & 2.17 & 2.04 to 2.31 & 6558 & 2.04 & 1.99 to 2.09 & 7601 & 2.06 & 2.01 to 2.10 \\
\hline $40-49$ & 5955 & 1.75 & 1.70 to 1.79 & 13996 & 1.56 & 1.53 to 1.58 & 19951 & 1.61 & 1.59 to 1.63 \\
\hline $50+$ & 7418 & 1.39 & 1.36 to 1.42 & 11129 & 1.32 & 1.30 to 1.35 & 18547 & 1.35 & 1.33 to 1.37 \\
\hline Two siblings & 2233 & 12.76 & 12.23 to 13.30 & 4651 & 9.25 & 8.99 to 9.52 & 6884 & 10.16 & 9.92 to 10.40 \\
\hline$<30$ & 155 & 20.39 & 17.31 to 23.87 & 1018 & 11.06 & 10.39 to 11.76 & 1173 & 11.77 & 11.11 to 12.47 \\
\hline $40-49$ & 909 & 13.70 & 12.83 to 14.62 & 1977 & 8.65 & 8.27 to 9.04 & 2886 & 9.79 & 9.43 to 10.15 \\
\hline $50+$ & 1169 & 11.56 & 10.91 to 12.25 & 1656 & 9.10 & 8.67 to 9.55 & 2825 & 9.98 & 9.62 to 10.36 \\
\hline Three siblings & 415 & 11.84 & 10.72 to 13.03 & 898 & 9.58 & 8.96 to 10.22 & 1313 & 10.19 & 9.65 to 10.76 \\
\hline$<30$ & 37 & 25.78 & 18.14 to 35.56 & 217 & 13.17 & 11.47 to 15.04 & 254 & 14.18 & 12.49 to 16.03 \\
\hline $40-49$ & 158 & 12.31 & 10.46 to 14.39 & 375 & 8.66 & 7.81 to 9.59 & 533 & 9.50 & 8.71 to 10.34 \\
\hline $50+$ & 220 & 10.58 & 9.23 to 12.08 & 306 & 9.00 & 8.02 to 10.06 & 526 & 9.60 & 8.79 to 10.45 \\
\hline $\begin{array}{l}\text { Four or more } \\
\text { siblings }\end{array}$ & 115 & 14.78 & 12.20 to 17.74 & 215 & 9.46 & 8.24 to 10.81 & 330 & 10.81 & 9.68 to 12.05 \\
\hline$<30$ & 15 & 39.80 & 22.21 to 65.80 & 66 & 15.06 & 11.65 to 19.17 & 81 & 17.02 & 13.52 to 21.16 \\
\hline $40-49$ & 49 & 16.56 & 12.25 to 21.91 & 80 & 7.85 & 6.23 to 9.78 & 129 & 9.81 & 8.19 to 11.66 \\
\hline $50+$ & 51 & 11.47 & 8.54 to 15.09 & 69 & 8.45 & 6.57 to 10.70 & 120 & 9.52 & 7.89 to 11.38 \\
\hline
\end{tabular}

O, observed number of cases; SIR, standardised incidence ratio. 


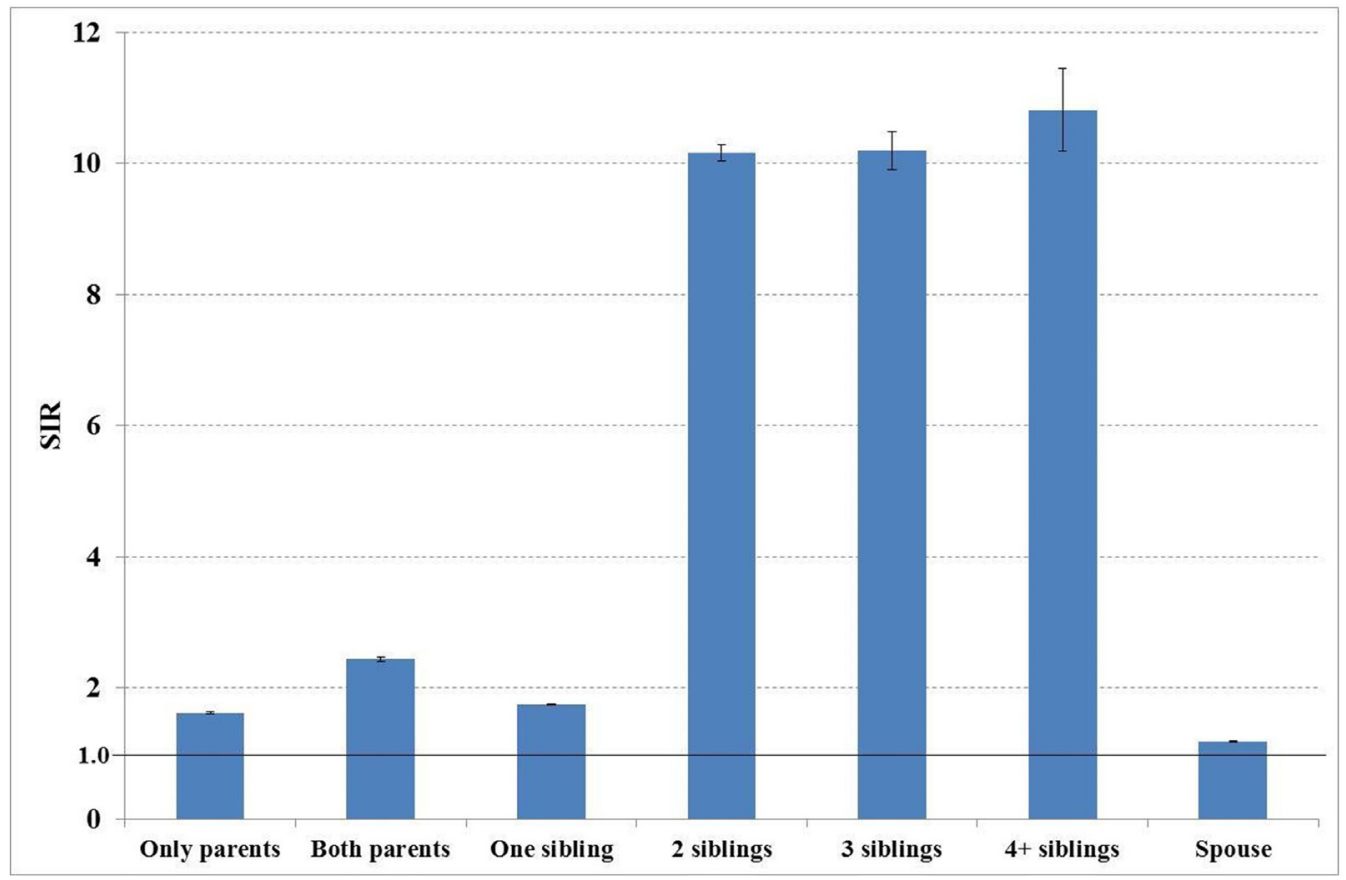

Figure 2 Familial risks (standardised incidence ratio (SIR) with $95 \% \mathrm{Cl}$ ) for gallstone disease depending on the types of affected family members, collected from tables 3 and 4 . The reference rate is at $S I R=1.00$.

about the importance of taking a detailed family history in the clinical setting and of targeting counselling accordingly.

Acknowledgements We are thankful to Patrick Reilly for language editing. Contributors $\mathrm{KH}$ and $\mathrm{OH}$ designed the study, KS and JS provided the datasets, $\mathrm{XL}$ and $\mathrm{KH}$ carried out analyses, $\mathrm{KH}$ wrote the manuscript, all authors helped to modify the interpretations and all authors approved the final text.

Funding This study was supported by Deutsche Krebshilfe and ALF grants of Region Skåne.

Competing interests None declared.

Provenance and peer review Not commissioned; externally peer reviewed.

Open Access This is an Open Access article distributed in accordance with the Creative Commons Attribution Non Commercial (CC BY-NC 4.0) license, which permits others to distribute, remix, adapt, build upon this work non-commercially, and license their derivative works on different terms, provided the original work is properly cited and the use is non-commercial. See: http://creativecommons.org/ licenses/by-nc/4.0/

(C) Article author(s) (or their employer(s) unless otherwise stated in the text of the article) 2017. All rights reserved. No commercial use is permitted unless otherwise expressly granted.

\section{REFERENCES}

1. Lammert F, Gurusamy K, Ko CW, et al. Gallstones. Nat Rev Dis Primers 2016;2:16024.

2. Krawczyk M, Stokes CS, Lammert F. Genetics and treatment of bile duct stones: new approaches. Curr Opin Gastroenterol 2013;29:329-35.

3. Stinton LM, Shaffer EA. Epidemiology of gallbladder disease: cholelithiasis and cancer. Gut Liver 2012;6:172-87.

4. Chen YC, Chiou C, Lin MN, et al. The prevalence and risk factors for gallstone disease in taiwanese vegetarians. PLoS One 2014:9:e115145.

5. Stokes CS, Krawczyk M, Lammert F. Gallstones: environment, lifestyle and genes. Dig Dis 2011;29:191-201.
6. Gurusamy KS, Davidson BR. Gallstones. BMJ 2014;348:g2669.

7. Sarin SK, Negi VS, Dewan R, et al. High familial prevalence of gallstones in the first-degree relatives of gallstone patients. Hepatology 1995;22:138-41.

8. Nakeeb A, Comuzzie AG, Martin L, et al. Gallstones: genetics versus environment. Ann Surg 2002;235:842-9.

9. Hsing AW, Bai Y, Andreotti G, et al. Family history of gallstones and the risk of biliary tract cancer and gallstones: a population-based study in Shanghai, China. Int J Cancer 2007;121:832-8.

10. van der Linden $\mathrm{W}$, Westlin $\mathrm{N}$. The familial occurrence of gallstone disease. II. Occurrence in husbands and wives. Acta Genet Stat Med 1966:16:377-82.

11. Joshi $A D$, Andersson $C$, Buch $S$, et al. Four susceptibility loci for gallstone disease identified in a meta-analysis of genome-wide association studies. Gastroenterology 2016;151:351-63.

12. Bergmann MM, Calle EE, Mervis CA, et al. Validity of self-reported cancers in a prospective cohort study in comparison with data from state cancer registries. Am J Epidemiol 1998;147:556-62.

13. Murff HJ, Spigel DR, Syngal S. Does this patient have a family history of cancer? An evidence-based analysis of the accuracy of family cancer history. JAMA 2004;292:1480-9.

14. Mai PL, Garceau AO, Graubard BI, et al. Confirmation of family cancer history reported in a population-based survey. J Natl Cancer Inst 2011;103:788-97.

15. Fiederling J, Shams AZ, Haug U. Validity of self-reported family history of cancer: a systematic literature review on selected cancers. Int J Cancer 2016;139:1449-60.

16. Frank $\mathrm{C}$, Fallah $\mathrm{M}$, Ji J, et al. The population impact of familial cancer, a major cause of cancer. Int J Cancer 2014;134:1899-906.

17. Kang JY, Ellis C, Majeed A, et al. Gallstones - an increasing problem: a study of hospital admissions in England between 1989/1990 and 1999/2000. Aliment Pharmacol Ther 2003;17:561-9.

18. Wadhwa V, Jobanputra Y, Garg SK, et al. Nationwide trends of hospital admissions for acute cholecystitis in the United States. Gastroenterol Rep 2017;5

19. Sandzén B, Haapamäki MM, Nilsson E, et al. Treatment of common bile duct stones in Sweden 1989-2006: an observational nationwide study of a paradigm shift. World J Surg 2012;36:2146-53.

20. Huang J, Chang $\mathrm{CH}$, Wang JL, et al. Nationwide epidemiological study of severe gallstone disease in Taiwan. BMC Gastroenterol 2009;9:63.

21. Williams E, Beckingham I, El Sayed G, et al. Updated guideline on the management of common bile duct stones (CBDS). Gut 2017;66:765-82. 